ORIGINAL ARTICLE

\title{
Validation of the Alder Hey Triage Pain Score
}

\author{
B Stewart, G Lancaster, J Lawson, K Williams, J Daly
}

Arch Dis Child 2004;89:625-630. doi: 10.1136/adc.2003.032599

See end of article for authors' affiliations

....................

Correspondence to: Dr B Stewart, Royal Liverpool Children's Hospital NHS Trust, Alder Hey, Eaton Road, Liverpool LAI 2AP, UK;

annebriar@aol.com

Accepted

12 November 2003

\begin{abstract}
Aims: To describe the validation and reliability of a new pain tool (the Alder Hey Triage Pain Score, AHTPS) for children at triage in the accident and emergency (A\&E) setting.

Methods: A new behavioural observational pain tool was developed because of dissatisfaction with available tools and a lack of confidence in self-assessment scores at triage. The study was conducted in a large paediatric A\&E department; 575 children (aged 0-16 years) were included. Inter-rater reliability and various aspects of validity were assessed. In addition this tool was compared to the Wong-Baker selfassessment tool.' The children were concurrently scored by a research nurse and triage nurses to assess inter-rater reliability. Construct validity was assessed by comparing the research nurse's triage score with the research nurse reassessment score after intervention and/or analgesia. Known group construct validity was assessed by comparing the research nurse's score at triage with the level of pain of the condition as judged by the discharge diagnosis. Predictive validity was assessed by comparing the research nurse's AHTPS with the level of analgesia needed by each patient. The AHTPS was also compared to a selfassessment score.

Results: A high level of inter-rater reliability, kappa statistic 0.84 (95\% Cl 0.80 to 0.88 ), was shown. Construct validity was well demonstrated; known group construct validity and predictive validity were also demonstrated to a varying degree.

Conclusions: Results support the use of this observational pain scoring tool in the triage of children in A\&E.
\end{abstract}

$\mathrm{T}$ he use of appropriate pain scoring tools has been recommended in recent guidelines published by both the Royal College of Nursing ${ }^{2}$ and the Royal College of Paediatrics and Child Health. ${ }^{3}$ The British Association of Emergency Medicine standard is for patients in severe pain (as determined by a pain score of 7-10) to have the prescription of analgesia within 20 minutes of arrival. ${ }^{4}$ However, studies have suggested that children's pain management in A\&E departments is suboptimal..$^{5} \mathrm{~A}$ large variety of paediatric pain scoring tools have been developed using different methods and designed for children with different cognitive ability, with no single score appropriate for all situations and age groups. ${ }^{6}$ Self-assessment tools are most commonly used. However, such tools were often originally developed for use in children experiencing postoperative or recurrent pain, for example, sickle cell crises. ${ }^{7}$ In these situations, there is an opportunity to explain how to use the tool prior to the painful experience. This clearly is not possible in an acute injury presenting to an A\&E department which demands urgent assessment to allow prompt treatment. In addition, the stresses and anxiety that occur with an unexpected painful experience disadvantage accurate selfassessment. ${ }^{8}$ The use of complex composite tools is confusing in this situation.

Formal pain tools and protocols have been shown to improve pain management in A\&E,' although levels of pain scoring still remain relatively low. Several visual analogue scale tools, many using a reference face scale, have been developed. Of these the Wong-Baker Faces Pain Rating Scale ${ }^{1}$ is probably best known and most widely used. The Toddler Pre-schooler Postoperative Pain Score (TPPPS $)^{10}$ is a behavioural tool which identifies and quantifies pain behaviours.

This tool has been tested in the A\&E setting, but it is inappropriate because, as the name implies, it is validated only for preschool children in a different setting. ${ }^{.1}$

Pain scoring commenced in the A\&E department at Alder Hey Children's Hospital in 1998 using a pain ladder, a composite tool including self-assessment, the Manchester Triage Pain Scale. ${ }^{12}$ This scale has never been formally validated and had a low level of uptake. Senior nursing staff felt that it was an unreliable method of assessing the level of a child's pain at triage and in addition that it was unhelpful in determining the level of analgesia required. Our experience was that children either quickly picked a value at random which often appeared to be out of proportion to the nature of the injury, appeared confused, or deferred to their parents for an answer. Self-assessment scores appeared to be more relevant after the initial presentation and are widely and successfully used in the inpatient setting in our hospital. For these reasons, we felt that this type of tool was not the most appropriate in A\&E.

\section{Development of tool}

The Alder Hey Paediatric Triage Score(AHTPS), was developed specifically for use with children at triage in A\&E departments (table 1). It is scored using observational and behavioural characteristics for assessment. Inquiry on pain related web discussion groups and personal correspondence to the Cochrane Pain, Palliative and Support Care Collaborative Group $^{13}$ and other paediatric A\&E departments, confirmed that there was no pain score validated in this field.

The departmental Multidisciplinary Pain Group discussed and identified the principle factors that experienced nurses had traditionally used to assess pain in children. In addition, the items in other behavioural/observational tools were studied, for example, CHEOPS ${ }^{14}$ and TPPPS. ${ }^{10}$ Key factors were agreed by the group, the departmental lead nurse, senior nursing staff, and two paediatric A\&E consultants. The items and description were then clarified by the group and the format agreed. Detailed explanation of the various categories was documented in unambiguous language to ensure uniform interpretation of the parameters. It was also decided that the tool must be in a format that was quick and easy to apply appropriate to the triage setting.

An initial assessment of the tool was performed by two groups of medical students working in the A\&E department. The results confirmed face and content validity and a high 
Table 1 The Alder Hey Triage Pain Score; reference scoring chart

\begin{tabular}{lllll}
\hline & Response & Score $\mathbf{0}$ & Score $\mathbf{1}$ & Score 2 \\
\hline 1. & Cry or voice & No complaint/cry & Consolable & Inconsolable \\
& Normal conversation & Not talking negative & Complaining of pain \\
2. Facial expression & Normal & Short grimace $<50 \%$ of time & Long grimace $>50 \%$ of time \\
3. Posture & Normal & Touching/rubbing/sparing & Defensive/tense \\
4. Movement & Normal & Reduced or restless & Immobile or thrashing \\
5. Colour & Normal & Pale & Very pale/"green" \\
\hline
\end{tabular}

level of inter-rater reliability and acted as pilot projects prior to the formal assessment of validity. ${ }^{15}{ }^{16}$ A change was made to the "cry/complaint" category to improve consistency of interpretation.

The aim of this study is to validate the AHTPS and to show it to be reliable in the paediatric A\&E setting. A validated tool that is appropriate for this purpose would be an important aid to rapid and accurate triage and management of painful conditions which are so commonly a challenge to health professionals in A\&E departments.

\section{METHODS}

A sample of 575 children, aged $0-15$ years, presenting to the A\&E department between January and July 2002 with a potentially painful condition, identified by the child, the carer, or the nature of the condition, were included in the study. Written consent for inclusion in the study was obtained from the child, parent, or carer after initial assessment. Children with immediate threat to life (triage category red) were excluded. Local Research and Ethics Committee approval was obtained for the study.

All triage nursing staff, 27 different nurses, were trained in the use of the AHTPS. Each member of the departmental pain group undertook a one to one discussion and education session with several of their colleagues until all staff were familiarised with the tool and had an opportunity to have any questions answered. These nurses then developed experience in its use at triage for about six months before the study commenced. During the study the AHTPS was not directly used to determine analgesia required. A senior research ( $G$ grade) nurse (JL) assessed the children's AHTPS at triage at the same time as the departmental triage nursing staff performed their standard assessment using the AHTPS. They were blinded to each other's scores. The scoring was repeated by the research nurse after 45 minutes on 310 of these children who had an intervention (for example, sling, splint etc), and/or analgesia to relieve their pain. The research nurse also documented a self-assessment Wong-Baker Face Score $^{1}$ for those children aged 3 and upwards with appropriate cognitive ability, both immediately after triage, and repeated the score after intervention and/or analgesia (292 children).

\section{Measures}

The Alder Hey Triage Pain Score (AHTPS)

Five categories of observations are identified: voice/cry, facial expression, posture, movement, and colour. Each of these has a possible score of 0,1 , or 2 , resulting in a total score ranging between 0 and 10. The reference scoring chart is shown in table 1 .

There is also a detailed description of each item provided on an additional sheet (see Appendix). Copyright for this tool was obtained in June 2002.

\section{Wong-Baker Faces Pain Rating Scale ${ }^{1}$}

This self-assessment tool shows a selection of six faces with different degrees of distress. After explanation the child is asked to pick the one that best represents their hurt. This scale ranges numerically from 0 to 10 in steps of 2 . The tool was used in the standard form as described by the authors. ${ }^{1}$

\section{Data analysis}

Methods of validation of pain scoring tools for children have been described by Beyer. ${ }^{17}$ We chose to look at inter-rater reliability and three aspects of validity. The analyses were performed using the statistical package Stats Direct. ${ }^{18}$

\section{Construct validity}

This is demonstrated if the tool is shown to conform to theoretical expectations, for example, that the pain score would decrease after therapeutic doses of analgesics. We therefore compared the AHTPS score taken by the research nurse before and after intervention and/or analgesia (310 children) using the Wilcoxon signed ranks test.

\section{Known group construct validity}

This is a particular type of construct validity, which compares the new score in different settings where the pain level should differ, for example, children experiencing a painful condition with those with a less painful condition. Each child was grouped into one of the following categories: no pain, mild pain, moderate pain, and severe pain. The groups were chosen as they represent groups that have a practical application to trigger the need to prescribe the appropriate level of analgesia. This was done by one author (BS) by examining the presenting complaint and discharge diagnosis of each individual record, based on her experience of those conditions having worked in paediatric A\&E medicine for nine years. A minor head injury might be expected to cause mild pain, whereas a compound displaced forearm fracture would be expected to cause severe pain. The AHTPS scores obtained by the research nurse at triage were then compared within each of these groups for all 575 children using Cuzick's trend test, ${ }^{19}$ and the strength of the association with diagnostic group assessed using Spearman's rank correlation coefficient.

\section{Predictive validity}

This is a type of validity that is demonstrated by using some external criteria (in our case the level of analgesia prescribed) to assess the level of pain experienced. The level of analgesia that the child was given was determined from the A\&E documentation. The children were sorted into four groups: no pain (none), mild (paracetamol), moderate (anti-inflammatory medication with or without paracetamol), strong (opiates). Differences in investigator AHTPS between the groups was assessed using Cuzick's trend test, and for strength of association using Spearman's rank correlation coefficient. Results were available on 476 patients. Ninety nine patients who refused analgesia were omitted.

\section{Reliability}

We assessed inter-rater reliability by comparing the AHTPS judged by the research nurse with that obtained by the triage 
nurse working concurrently but blinded from each other's score. Agreement was measured by a kappa statistic ${ }^{20}$ for all 575 patients, using the criteria defined by Landis and $\mathrm{Koch}^{21}$ for agreement: kappa values $<0.2$ indicate poor agreement, $>0.2-0.4$ fair agreement, $>0.4-0.6$ moderate agreement, $>0.6-0.8$ good agreement, and $>0.8$ very good agreement.

AHTPS versus Wong-Baker Faces Pain Scale As there is no validated gold standard pain tool in this area, demonstration of concurrent validity was not possible. We chose to compare the tool with the Wong-Baker Faces Pain Scale. ${ }^{1}$ The research nurse collected the scores both at triage and after intervention using the appropriate method described. ${ }^{1}$ We wanted to illustrate and understand the relation between the two tools and determine whether our previous reservations about self-assessment could be demonstrated. Spearman's rank correlation was used to compare the two test scores, because a kappa statistic could not be calculated for scores using different scales. Reservations about comparing a five point scale with a ten point scale were acknowledged, although reference to such comparisons is found on the web site ${ }^{1}$ and stated to be acceptable. The AHTPS of only the 292 children who had the cognitive ability to use the self-assessment score ( 3 years of age or over) were included in the comparison.

\section{Sample size}

It was determined that in order to calculate an estimated kappa of 0.7 to an accuracy of $\pm 5 \%$, using a $95 \%$ confidence interval, a sample size of 500 children would be necessary ${ }^{22}$

\section{RESULTS}

Five hundred and seventy five children (male 59\%, female $41 \%$ ) were recruited into the study. No parent approached refused entry into the study. The median age of the children was 10 years (IQR 5-12) and included 10 children (2\%) less than 1 year of age.

The diagnoses reflected the spectrum of clinical conditions presenting to the department. Soft tissue injuries represented $33 \%$, lacerations $20 \%$, fractures $18 \%$, and abdominal pain $5 \%$. One hundred and eighty five children had some form of intervention: sling $11 \%$, wheelchair $11 \%$, dressing 5\%. Three hundred and fifty four children received analgesia; an additional 99 who were offered analgesia, refused. Analgesic medication and pain relieving intervention were used either in combination or alone as clinical need dictated by the staff caring for the patient at the time. $1-3)$.

The median AHTPS at triage in all patients was 2 (IQR

\section{Construct validity}

The comparison of the pain score before and after analgesia

There was a significant difference in the pain scores taken by the investigator before and after intervention (median (IQR) $3(2-4) \vee 2(1-2), p<0.001)$, showing the ability of the pain tool to distinguish between differing levels of pain before and after treatment.

\section{Known group construct validity}

The comparison of pain score with pain expected by diagnostic group (based on experience)

The correlation of AHTPS with diagnostic group was not well demonstrated ( $\mathrm{r}=0.57,95 \% \mathrm{CI} 0.51$ to 0.62 ). However, the box and whisker plot in fig 1 indicates rising pain levels for each diagnostic group of children, grouped according to the severity of their discharge diagnoses. This trend was significant using Cuzick's trend test $(\mathrm{p}<0.001) .{ }^{19}$

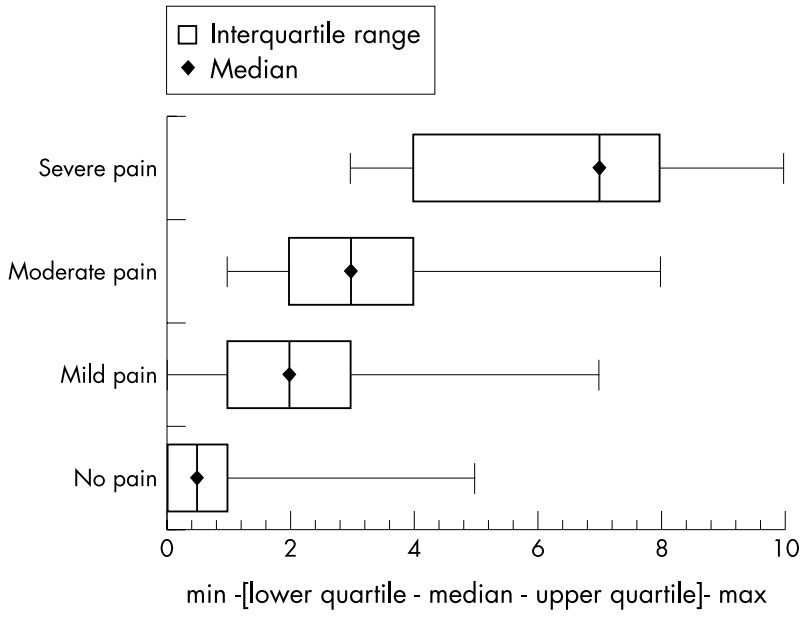

Figure 1 Known groups construct validity: investigator AHTPS (minimum value, interquartile range, median, maximum value) by expected pain level from discharge diagnosis group (by experience).

\section{Predictive validity}

The comparison of the pain score with the level of analgesia prescribed

Rising pain levels were again apparent when the children were grouped by level of analgesia required, as shown in fig 2 . There was a high association with analgesic group $(\mathrm{r}=0.80$, 95\% CI 0.76 to 0.83 ), which produced a significant trend in pain levels $(p<0.001)$ using Cuzick's trend test. ${ }^{19}$

\section{Reliability}

The blinded comparison of two simultaneous pain scores by different triage nurses

There was a very high level of agreement in pain scores between the investigator and triage nurse, with a kappa value of 0.84 (95\% CI 0.80 to 0.88 ), indicating that the tool was reliable for use at triage.

\section{Comparison of AHTPS with Wong-Baker Faces Pain Score}

The association between the investigator AHTPS (a behavioural/observational score ) and the Wong-Baker Faces Pain Score (self-assessment) scores was lower at triage $(\mathrm{r}=0.46$, $95 \%$ CI 0.37 to 0.55$)$ than after intervention $(r=0.53,95 \%$ CI

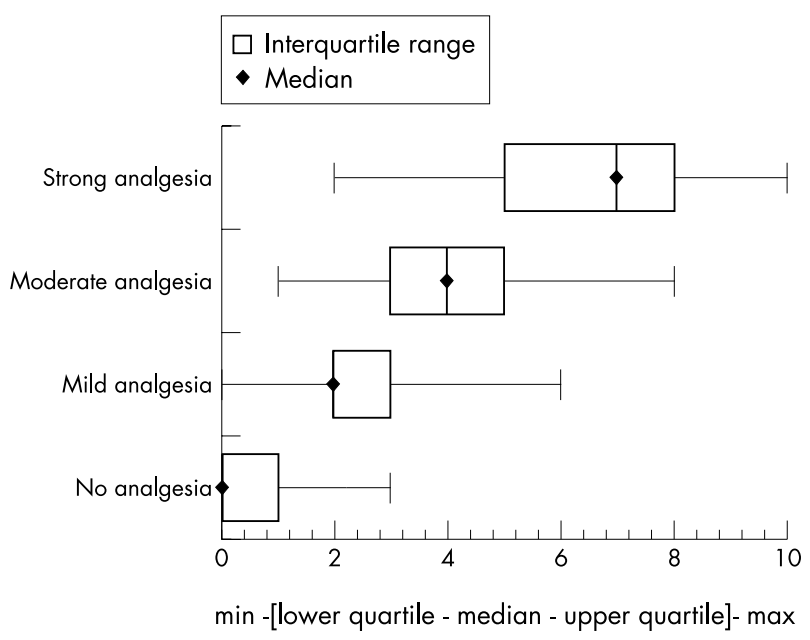

Figure 2 Predictive validity: investigator AHTPS (minimum value, interquartile range, median value, maximum value) by level of analgesia prescribed. 


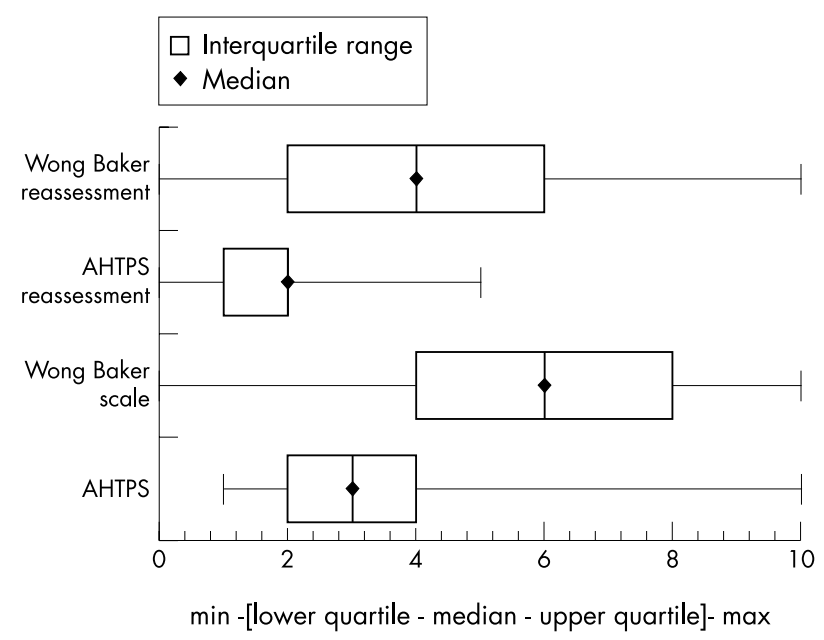

Figure 3 Investigator AHTPS $v$ Wong-Baker faces self-assessment scale, at presentation and at reassessment (minimum value, interquartile range, median, maximum value).

0.45 to 0.61 ). This is illustrated in table 2 which gives the raw scores, and is summarised in fig 3, the investigator indicating a lower pain score than the child.

\section{DISCUSSION}

Evaluating a child's pain is a complex subject and the optimum measure may vary according to the child's age, cognitive development, type of pain, and presenting situation. ${ }^{5}$ Our tool was developed specifically for the A\&E setting, choosing an observational model that we applied in the first instance to all ages. We recognise that this tool is open to interpreter bias, but this can be minimised by instigating a good staff training programme to promote uniformity of interpretation. The nature of pain is complex and multifactorial, and aspects of the observations in our tool could be influenced by factors other than pain itself. It is important therefore to use the tool accurately and in context.

The Alder Hey Triage tool has a high degree of inter-rater reliability. A kappa statistic of $>0.8$ represents a high degree of agreement ${ }^{21}$ and this is specifically considered to be adequate in assessing inter-rater reliability of behavioural tools. ${ }^{17}$ In our study this high degree of agreement was shown despite the involvement of 27 different members of nursing staff triaging patients. This is important since in reality, in the A\&E setting, the tool is likely to be used by a large number of nursing staff when triaging patients. The tool was found to be quick and easy to use and staff training was easily achieved by individual discussions of about 10 minutes and then supervised use at triage for part of a shift. Members of the pain team were also available to discuss individual concerns with interpretation as they arose.

The study demonstrated construct validity for conditions presenting during the normal day to day activity of a paediatric A\&E department. Predictive validity was shown with the reservation that although the pain score was not directly used to determine the analgesia prescribed but as part of a multi-factorial assessment, it cannot be assumed this was an entirely independent measure. However, in cases other than mild pain the level of analgesia needed was not assessed during this study by the triage (scoring) nurse.

Known group construct validity was less well demonstrated, probably reflecting the difficulty of allocating pain levels from the underlying diagnosis of the condition itself, which had a subjective element from the author assigning the "known groups". In addition individuals' pain perception to a certain injury varies. Both these factors would confound precise categorisation. It was however felt to be worth considering for conditions at either end of the spectrum and it did contribute to the overall assessment of the tool.

These results together support the relevance of using the tool in this setting.

Comparison of the AHTPS with the self-assessment tool supported our perception that often children select a relatively high value at first. The relatively poor correlation is a reflection of this but also illustrates the problem of self assessment at triage which was the reason for developing our tool. If the correlation had been very good the need for a new tool would be questionable. We anticipated that the values of AHTPS and the Wong-Baker Faces Pain Scale scores would be closer after intervention when the child has had opportunity to feel more at ease in the department and to

Table 2 Cross-tabulation of investigator AHTPS with Wong-Baker Faces Self-assessment Scale at triage and after intervention

\begin{tabular}{|c|c|c|c|c|c|c|}
\hline \multirow[b]{2}{*}{ AHTPS } & \multicolumn{6}{|c|}{ Wong-Baker } \\
\hline & 0 & 2 & 4 & 6 & 8 & 10 \\
\hline \multicolumn{7}{|c|}{ At triage } \\
\hline 1 & 3 & 12 & 17 & 10 & 6 & 0 \\
\hline 2 & 0 & 10 & 22 & 28 & 15 & 4 \\
\hline 3 & 0 & 5 & 21 & 34 & 25 & 5 \\
\hline 4 & 0 & 1 & 5 & 12 & 13 & 5 \\
\hline 5 & 0 & 0 & 2 & 1 & 9 & 3 \\
\hline 6 & 0 & 0 & 2 & 1 & 4 & 0 \\
\hline 7 & 0 & 0 & 0 & 1 & 5 & 2 \\
\hline 8 & 0 & 0 & 0 & 1 & 2 & 2 \\
\hline 9 & 0 & 0 & 0 & 0 & 0 & 2 \\
\hline 10 & 0 & 0 & 0 & 0 & 0 & 2 \\
\hline \multicolumn{7}{|c|}{ After intervention } \\
\hline 0 & 25 & 0 & 0 & 0 & 0 & 0 \\
\hline 1 & 3 & 35 & 20 & 11 & 1 & 1 \\
\hline 2 & 0 & 43 & 48 & 31 & 9 & 1 \\
\hline 3 & 1 & 7 & 11 & 25 & 12 & 0 \\
\hline 4 & 0 & 0 & 4 & 0 & 1 & 0 \\
\hline 5 & 0 & 0 & 1 & 0 & 1 & 1 \\
\hline
\end{tabular}


Table A1 Explanatory notes of observational pain scores

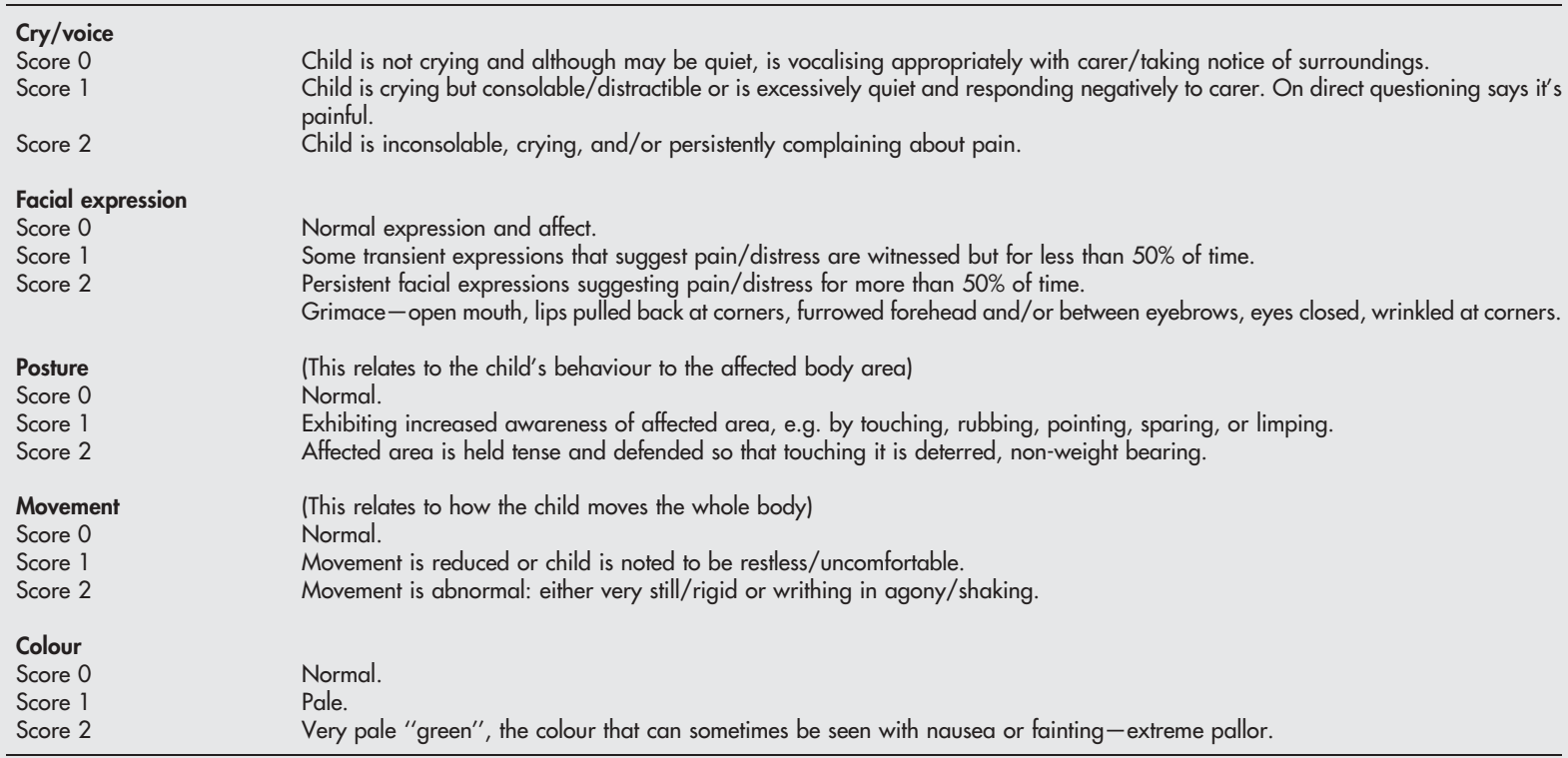

become familiar with the self-assessment score, ${ }^{7}$ and this was confirmed. Although there is no validated gold standard pain scoring tool in our setting and differences between selfassessment parental, nursing, or doctor assessment of a child's pain can be quite marked, ${ }^{23}$ the ideal tool is one which can be used with confidence by the staff to enable prompt pain management.

We would still advocate the early introduction to selfassessment tools for children after triage in the A\&E department, especially for those likely to be admitted and/ or who require repeated assessment of their pain, where there is the opportunity to explain the scoring system and become familiar with it.

Other A\&E departments ${ }^{24}$ have reported difficulties with self-assessment tools for pain at triage in adult patients. For these patients there may be other factors that bias selfassessment values such as the perception that they will be seen and assessed more quickly or that they are more likely to be treated with strong opiate based analgesia. We suggest that the tool may also be validated for use in these departments.

We propose to continue to study and refine the tool further by looking at the internal reliability of the individual categories. In addition the tool will be studied for a variety of age groups (in particular its relevance to children $<1$ year). We recommend further validity studies, but we believe that it can be used and will benefit children, allowing more prompt and appropriate management of their pain at triage in A\&E departments.

\section{ACKNOWLEDGEMENTS}

We would like to thank the nursing and medical staff in the A\&E department at Alder Hey Children's Hospital; in particular the A\&E Pain Group. In addition we would express our thanks to the children and families who agreed to participate.

\section{Authors' affiliations}

B Stewart, J Lawson, K Williams, J Daly, Royal Liverpool Children's Hospital NHS Trust, Alder Hey, Liverpool, UK

G Lancaster, Centre for Medical Statistics and Health Evaluation, University of Liverpool, Liverpool, UK
APPENDIX: EXPLANATION SHEET FOR THE AHTPS

Explanatory notes of observational pain scores are presented in table Al.

\section{REFERENCES}

1 Wong D. Wong on web. www.harcourthealth.com/Mosby/Wong

2 The Royal College of Nursing. The recognition and assessment of acute pain in children. Clinical Practice Guidelines. Oxford: RCNI, 1999.

3 The Royal College of Paediatrics and Child Health. Recognition and assessment of acute pain in children. Guidelines for Good Practice. London: RCPCH, 2001.

4 The British Association for Accident and Emergency Medicine, Clinical Effectiveness Committee. Standards for accident and emergency departments. London: BAEM, January 2002.

5 Somers LJ, Beckett MW, Sedgewick PM, et al. Improving the delivery of analgesia to children in pain. Emerg Med J 2001;18:159-61.

6 McGrath P. Evaluating a child's pain. J Pain Symptom Manage 1989;4:198-214.

7 Beyer J, Aradine C. Patterns of pediatric pain intensity: a methodological investigation of a self-report scale. Clin J Pain 1987;3:1130-41.

8 Ross D, Ross A. The importance of question, psychological climate and subject set in interviewing children about pain. Pain 1984;19:71-9.

9 Kelly A. A process approach to improving pain management in the emergency department: development and evaluation. J Accid Emerg Med 2000;17:185-7.

10 Tarbell SE, Cohen IT, Marsh JL. The Toddler-Preschooler Postoperative Pain Scale: an observational scale for measuring post-operative pain in children aged 1-5. Preliminary report. Pain 1992;50:273-80.

11 McCarthy C, Hewitt S, Choonara I. Pain young children attending an accident and emergency department. J Accid Emerg Med 2000;17:265-7.

12 Advanced Life Support Group. Advanced paediatric life support. The practical approach, 3rd edn. London: BMJ Publications, 2001.

13 Cochrane Pain Palliative and Support Care Collaborative Review Group. Pain Relief Unit, The Churchill Hospital, Oxford, UK.

14 McGrath PJ, Johnson G, Goodman JT, et al. CHEOPS: a behavioural scale for rating post operative pain in children. In: Fields HL, DubnerR, Cervero F, eds. Advances in pain research and therapy. New York: Raven Press, 1985;9:395-402.

15 Bunstone D, Chhina N. Special study module 4. University of Liverpool, December, 1999.

16 Davis E, Rostron M. Special study module 6. University of Liverpool, July 2000.

17 Beyer J. Key issues surrounding the assessment of pain in children. Paediatric and Perinatal Drug Therapy 1998;2:3-13.

18 StatsDirect Ltd. StatsDirect Statistical software version 1.9.11. lain Buchan 1990-2002. http://www.statsdirect.com.

19 Cuzick J. A Wilcoxon-type test for trend. Stat Med 1985;4:87-9.

20 Fleiss JL. Statistical methods for rates and proportions, 2nd edn. New York: Wiley, 1981.

21 Landis R, Koch $\mathrm{G}$. The measurement of observer agreement for categorical data. Biometrics 1977;33:159-74.

22 Streiner D, Norman G. Health measurement scales: a practical guide to their development and use, 2nd edn. Oxford: Oxford University Press, 1995.

23 Kelly A, Powell C, Williams A. Parent visual analogue scale ratings of children's pain do not reliably reflect pain reported by child. Pediatr Emerg Care 2002;18:159-62.

24 Lipley N. Painful lessons. Emergency Nurse 2002;10(1):5 


\section{IMAGES IN PAEDIATRICS}

\section{The first Children's Charter}

$\int$ anusz Korczak (Dr Henryk Goldszmit) (1878/9-1942) is a man of whom the majority of paediatricians are unaware. A doctor, early child psychologist, children's advocate, writer, broadcaster and playwright, he pioneered in his practice and ideas many areas which today would be regarded as mainstream paediatric care. He was a man who devoted his life to children and their welfare.

An early children's advocate, he wrote the first Children's Charter. "Korczak spoke of the need for a Declaration of Children's Rights long before any such document was drawn up by the Geneva Convention (1924) or the United Nations General Assembly (1959). The Declaration he envisaged—not a plea for good will but a demand for action-was left uncompleted at the time of his death". ${ }^{1}$

His last years were spent running a children's home in the Warsaw Ghetto during the early years of the Second World War.

In August 1942, he and the children were marched to the railway station for transportation for "resettlement". At the station he was recognised by a German medical officer who gave him the chance to save himself. He declined with the words "One does not leave a sick child-my place is with them".

\section{The child has the right to love.}

(Korczak: "Love the child, not just your own."

The child has the right to respect.

(Korczak: "Let us demand respect for shining eyes, smooth foreheads, youthful effort and confidence. Why should dulled eyes, a wrinkled brow, untidy gray hair, or tired resignation command greater respect?")

The child has the right to optimal conditions in which to grow and develop.

(Korczak: "We demand: do away with hunger, cold, dampness, stench, overcrowding, overpopulation.")

The child has the right to live in the present.

(Korczak: "Children are not people of tomorrow; they are people today.")

The child has the right to be himself or herself.

(Korczak: "A child is not a lottery ticket, marked to win the main prize.")

The child has the right to make mistakes.

(Korczak: "There are no more fools among children than among adults.")

The child has the right to fail.

(Korczak: "We renounce the deceptive longing for perfect children.")

The child has the right to be taken seriously.

(Korczak: "Who asks the child for his opinion and consent?")

The child has the right to be appreciated for what he is

(Korczak: "The child, being small, has little market value.")

The child has the right to desire, to claim, to ask.

(Korczak: "As the years pass, the gap between adult demands and children's desires becomes progressively wider.")

The child has the right to have secrets.

(Korczak: "Respect their secrets.")
He kept to his word. He and the children were taken to Treblinka-an extermination camp.

No one survived.

Nowadays the accuracy of words is often debased and it is all too easy to become self absorbed and forget the very real struggles that have and are still being fought for the rights of children in this world.

Janusz Korczak and the events of his time still have much to teach us.

This table is taken from The King of Children by Betty Jean Lifton and is compiled by her from Korczak's works: How to Love a Child and The Child's Right to Respect from those rights which Korczak felt most essential.

I have found this biography inspirational and I would unhesitatingly recommend it to any who are interested in child health.

A N Williams

Child Development Centre, Northampton General Hospital, Northampton NN1 5BD, UK; anw@doctors.org.uk doi: $10.1136 /$ adc. 2003.031682

\section{Reference}

1 Lifton BJ. The King of Children. London: Pan Books Ltd, 1989:355-6.

The child has the right to "a lie, a deception, a theft".

(Korczak: "He does not have the right to lie, deceive, steal.")

The child has the right to respect for his possessions and budget.

(Korczak: "Everyone has the right to his property, no matter how insignificant or valueless.")

The child has the right to education.

The child has the right to resist educational influence that conflicts with his or her own beliefs.

(Korczak: "It is fortunate for mankind that we are unable to force children to yield to assaults upon their common sense and humanity.")

The child has the right to protest an injustice.

(Korczak: "We must end despotism.")

The child has the right to a Children's Court where he can judge and be judged by his peers.

(Korczak: "We are the sole judges of the child's actions, movements, thoughts, and plans. I know that a Children's Court is essential, that in fifty years there will not be a single school, not a single institution without one.")

The child has the right to be defended in the juvenilejustice court system.

(Korczak: "The delinquent child is still a child. Unfortunately, suffering bred of poverty spreads like lice: sadism, crime, uncouthness, and brutality are nurtured on it.")

The child has the right to respect for his grief.

(Korczak: "Even though it be for the loss of a pebble.")

The child has the right to commune with God.

The child has the right to die prematurely.

(Korczak: "The mother's profound love for her child must give him the right to premature death, to ending his life cycle in only one or two springs. Not every bush grows into a tree.") 